\title{
ACERCA DE LA INVERSIÓN DEL PLATONISMO EN NIETZSCHE Y HEIDEGGER
}

\author{
About the Reversal of Platonism \\ in Nietzsche and Heidegger
}

Juan Luis Vermal

Universidad Islas Baleares

\begin{abstract}
RESUMEN: Después de hacer algunas consideraciones hermenéuticas sobre el carácter de la lectura heideggeriana de Nietzsche, el artículo intenta seguir el desarrollo de la tesis de que el pensamiento de este último es una inversión del platonismo, conjuntamente con la pregunta acerca de si esta inversión da lugar a un abandono del platonismo, teniendo en cuenta tanto el texto del libro sobre Nietzsche publicado en 1961 como el de las lecciones originales, las notas para el seminario sobre Nietzsche de 1937 y los Beiträge zur Philosophie. En este contexto se revela la centralidad de la cuestión de la verdad para toda la interpretación de Heidegger, y se sigue la discusión crítica de los conceptos relacionados de «apariencia», "perspectivismo» e «interpretación». A continuación se señala lo que para Heidegger constituye el paso decisivo: la comprensión de la verdad como justicia. En relación con lo anterior se expone por último el cambio que se produce en la concepción de la verdad del propio Heidegger.

Palabras claves: platonismo - verdad - apariencia - perspectivismo - interpretación.
\end{abstract}

ABSTRACT: After some considerations on the nature of Heidegger's reading of Nietzsche, the article traces the development of the thesis that Nietzsche's philosophy is an inversion of Platonism, together with the question whether it leads or not to an abandonment of Platonism, making reference to the book published in 1961 as well as to the original lessons, the notes for the seminar on Nietzsche of 1937, and the Beiträge zur Philosophie. In this context the centrality of the question of truth for the whole interpretation of Heidegger is pointed out and a critical discussion of the related concepts of «appearance», «perspectivism» and «interpretation» is engaged. Subsequently, the article presents what Heidegger takes for the decisive step: the understanding of truth as «justice». In connection with the previous discussion, it finally describes the change operated in Heidegger's own conception of truth.

Keywords: platonism - truth - appearance - perspectivism - interpretation.

A lo largo de la extensa Auseinandersetzung que emprende con Nietzsche en la segunda mitad de los años treinta, Heidegger no lleva a cabo simplemente una interpretación crítica de Nietzsche sino algo mucho más complejo y profundo: un intento de deconstrucción interna de la metafísica, y especialmente de la metafísica de la subjetividad, que es al mismo tiempo un intento de pensar una transformación radical de Occidente. Esto va acompañado, de manera más o 
menos explícita, de una necesidad de construcción desde aquello desde donde se ha realizado el proceso destructivo. Es desde aquí desde donde cabe un enfrentamiento fructífero con la lectura heideggeriana.

Hay que hacer, pues, una reserva hermenéutica que con mucha frecuencia se pasa por alto. La lectura de Heidegger no es una interpretación usual que intentaría presentar «lo que Nietzsche realmente dijo», sino que lo interpreta desde un proyecto, intentando sacar a la luz lo no dicho, pero que de cierto modo subyace y ordena. Esto, que no elimina otras posibles lecturas de ciertas ideas de Nietzsche, encuentra su piedra de toque en una comprensión epocal que se puede leer en algunas de sus tesis, precisamente en la medida en que se muestra fiel a un nivel profundo que se trata entonces de rescatar. Precisamente por eso hay que tener en cuenta la advertencia de Heidegger de que no tiene sentido refutar proposiciones esenciales tales como la de que «la verdad es una ilusión», porque una frase de este tipo «remite a un fundamento que no puede eliminarse sino que, por el contrario, sólo exige que se ahonde en él de manera más profunda» ${ }^{1}$.

Desde un comienzo Heidegger consideró a Nietzsche como el final de la metafísica. En la primera de las lecciones ${ }^{2}$ aparece ya tal afirmación, aunque quizás ocupe allí un lugar más ambiguo que posteriormente. Efectivamente, al comienzo de esas lecciones, y a propósito de la planeada edición de obras completas, Heidegger señala que la preparación de la «auténtica 'obra' (1881-1889)» sólo podrá llevarse a cabo seriamente si se ha comprendido a Nietzsche «como el final de la metafísica occidental» y se ha pasado ya a la pregunta por la verdad del ser $»^{3}$. La cuestión del «final» es decisiva, aunque sólo es visible desde el «nuevo inicio» ${ }^{4}$. Este paso constituye el lugar desde donde están pensadas estas lecciones y es lo que sale a la luz con toda claridad en los Beiträge ${ }^{5}$, escritos en la misma época y que constituyen el fondo sobre el cual y desde el cual deben leerse las lecciones sobre Nietzsche. La relación entre el primer inicio, el inicio griego, y el otro inicio, el que se abre con el final del primero, aunque éste sólo es comprensible a su vez desde aquel, constituye la línea maestra que tensa el movimiento de esta obra nacida póstuma. El carácter de ese tránsito resulta esencial para toda la meditación heideggeriana, desde el momento en que claramente no puede tratarse de un mero cambio epocal, de una época más que se sume a las anteriores, sino que pone en juego el concepto mismo de historia en el que se basaría tal sucesión. Por eso mismo resulta especialmente importante ver cómo intenta pensar Heidegger en cada caso esa línea de ruptura.

Si Nietzsche se vuelve tan decisivo para Heidegger es, en gran parte, porque ha experimentado precisamente esa ruptura, lo cual significa: identificado el comienzo, o sea el pensamiento griego platónico, vivido la crisis que impone el

1. M. Heidegger, Nietzsche, 2 vols., Pfullingen: Neske, 1961, t. I, p. 503; trad. de J. L. Vermal, Barcelona: Destino, 2000, t. I, p. 406. De ahora en adelante se citará Nietzsche I (tomo), 503 (orig.)/406 (trad.).

2. «La voluntad de poder como arte» (1936/1937), recogida en Nietzsche I. La versión original de las lecciones ha aparecido en el marco de las obras completas: M. Heidegger, Gesamtausgabe, Frankfurt a. M.: Klostermann, 1975 ss. (en adelante GA), vol. 43.

3. Nietzsche I, 19/25.

4. Nietzsche I, 241/197.

5. Beiträge zur Philosophie (Vom Ereignis) (1936-1938), GA 65, 1989 (Aportes a la filosofía. Acerca del evento, trad. de D. V. Picotti, Buenos Aires: Almagesto/Biblos, 2003). 
final de ese camino (el nihilismo) y señalado la necesidad de la transformación (la transvaloración, la figura del superhombre). Todo esto hace que el final que representa Nietzsche no sea de ninguna manera un mero acabarse sino que pueda y deba ser leído como una «transición» (Übergang), que es «lo más alto que puede decirse de un pensador ${ }^{6}$.

Es esa comprensión de la ruptura, basada en los tres elementos citados, lo que hace a Nietzsche tan cercano a Heidegger, hasta el punto de intentar por momentos, sobre todo en la primera fase de la controversia, una interpretación de los temas centrales (voluntad de poder, eterno retorno) paralela a su propios planteamientos, de manera tal que aquellos lleguen al punto en que puedan transmutarse y señalar más allá de sí. Esto último se vuelve necesario desde el momento en que advierte que el modo en que Nietzsche ha articulado ese movimiento de ruptura, a pesar de su carácter de algún modo paradigmático, queda enredado en lo que intenta romper por no poder volver al inicio originario sino comprenderlo ya desde lo que es una derivación ocultadora del mismo. Y esto es así porque no parte en general de la cuestión de base que por un lado domina toda la tradición metafísica y, por otra, jamás se plantea en su interior: la cuestión de ser y la correspondiente cuestión de la verdad.

La posición de Nietzsche respecto de la metafísica es interpretada, sobre todo en las lecciones recogidas en el primer tomo del Nietzsche, en conexión con el «platonismo» y con la posible inversión de la relación entre un «mundo verdadero» y un «mundo aparente». Tal interpretación se mueve, como resulta obvio, en el contexto de una exposición y discusión del sentido de verdad presente en Nietzsche, y con el trasfondo de la propia concepción heideggeriana de la verdad. Esto es así hasta el punto de que podría decirse que toda la confrontación con Nietzsche se mueve siguiendo el hilo conductor de la cuestión de la verdad.

Heidegger comienza su interpretación apoyándose en la formulación del propio Nietzsche de que «mi filosofía es un platonismo invertido» ${ }^{8}$. Si la metafísica es esencialmente la división de dos mundos, un mundo verdadero, constituido por lo que propiamente «es», es decir permanente e inmutable, y lo que no es más que apariencia, es decir lo sensible y cambiante, la inversión de la metafísica tendría que consistir, ante todo, en la afirmación del «mundo aparente» como único mundo real, y la relegación del «mundo verdadero» al carácter de apariencia. La inversión se repite, como es evidente, en otras oposiciones típicamente metafísicas, como la de cuerpo y alma o espíritu y materia, pero su punto central se encuentra en la concepción de la verdad. La interpretación de Heidegger gira alrededor de la pregunta por la naturaleza de esa inversión y de lo que acontece una vez que se ha realizado. Trataremos de seguir ese camino, comentando al mismo tiempo la discusión que realiza de conceptos relacionados, como el de apariencia o interpretación.

Es evidente que una simple inversión de los términos de una oposición sigue pendiente del esquema que plantea tal división. A pesar de ello, Heidegger no

6. GA 43, 278 .

7. «Decimos platonismo, y no Platón, porque no documentaremos aquí la concepción del conocimiento en cuestión de modo original y detallado en la obra de Platón, sino que sólo destacaremos sin entrar en detalles un rasgo determinado por él», Nietzsche I, 177/148.

8. KSA VII, 7[156]. Citado en Nietzsche I, 180/150 
subestimaba la importancia de esa inversión. En un pasaje de las lecciones de 1936/37 que no fue recogido en el libro de 1961 afirma que «esa inversión es el comienzo de un sacudimiento de los fundamentos más íntimos de la bimilenaria historia occidental»". A pesar de ello, o quizás más bien por ello, por la dinámica encerrada allí, también recalca que el propio Nietzsche ve que una inversión de este tipo no deja subsistir la oposición anterior y tiende por lo tanto a su destrucción y a salirse del esquema fijado por ella, y por lo tanto del platonismo. Heidegger formula esta disyuntiva con términos muy plásticos, preguntándose si se pasa de la Umdrehung (inversión, giro que invierte) a una Herausdrehung (expulsión, giro que expulsa).

Así pues, si hay una inversión de la relación mundo verdadero-mundo aparente, resulta que el mundo aparente se convierte en el auténtico mundo verdadero, mientras que el mundo verdadero platónico es una apariencia resultado de la detención y fijación de lo aparente, de la (falsa) atribución de un valor de verdad. El hilo conductor de buena parte de la interpretación consiste en mostrar lo que acontece con esa inversión, que no puede limitarse a ser una simple inversión. El testimonio de que no podía serlo aparece ya en la afirmación Nietzscheana de que «apariencia es la realidad única y efectiva de las cosas» ${ }^{10}$. Para Nietzsche, esto no significa una supervivencia de la división platónica, sino que señala ante todo que el carácter de lo real mismo no es el de una identidad en sí verdadera. Lo que es, lo que desde los griegos se llama «ente», no tiene, paradójicamente, el carácter de ser, y por lo tanto no se lo puede tratar como tal. Visto desde la verdad: la verdad es una especie de falsedad, y no sólo tal o cual verdad sino el concepto mismo de verdad. No se trata tampoco de una afirmación escéptica, sino que quiere decir que verdad, en la medida en que es la fijación de un contenido determinado, es ya una falsificación. ¿Respecto de qué? Respecto del mundo «verdadero» o «real», que precisamente no se deja captar con esas categorías. El sentido de la afirmación del carácter aparente de lo real se asoma a este abismo.

La cuestión de la inversión y la posible salida del platonismo la analiza Heidegger en su lectura del conocido texto de El crepúsculo de los ídolos «Cómo el 'mundo verdadero' acabó convirtiéndose en una fábula» ${ }^{11}$. Los seis períodos de la «historia del platonismo» terminan, dice Heidegger, con la expulsión fuera de él (Herausdrehung) ${ }^{12}$. El quinto y penúltimo de los períodos había descrito la abolición del «mundo verdadero». La abolición del mundo verdadero platónico deja como verdad al mundo sensible, manteniéndose invertida la estructura de un arriba y un abajo propio del platonismo. Lo decisivo aparece entonces en el sexto y último período: «Hemos suprimido el mundo verdadero: ¿qué mundo queda? ¿el aparente quizá?...iPues no! icon el mundo verdadero también hemos suprimido el aparente!».

El añadido de este período final muestra para Heidegger que Nietzsche «tiene que ir más allá de sí mismo y de la mera supresión de lo suprasensible» ${ }^{13}$. El «nuevo orden jerárquico no quiere simplemente invertir los términos dentro del

9. GA 43, 218.

10. KSA XI, 40[53].

11. KSA VI 80 s. (CI, Madrid, Alianza, 1973, pp. 57 s.).

12. Nietzsche I 235/192, 240/196.

13. Nietzsche I 240/196. 
viejo esquema», sino que significa «alterar el esquema de orden. En ese sentido, la inversión tiene que convertirse en una expulsión fuera del platonismo» ${ }^{14}$. No queda claro, sin embargo, "hasta qué punto llega a una superación del platonismo y hasta qué punto no».

En las lecciones originales, lo anterior, que parece dejar una posibilidad abierta, estaba seguido de dos páginas que responden a la pregunta planteada de forma más contundente y que no fueron recogidas en el libro de $1961^{15}$. En ellas sostiene Heidegger que la voluntad de Nietzsche es ciertamente la de pasar de la inversión a la expulsión, pero, se pregunta, «¿̇e elimina con ello la distinción entre verdad y apariencia?, ¿̇se la puede eliminar, y si no se puede, ¿̇por qué?». Nietzsche no se plantea ya estas preguntas, lo que significa para Heidegger que la cuestión de la verdad no accede a un nivel suficientemente profundo. Nietzsche no elimina, por lo tanto, la verdad y su diferencia con la no verdad y la apariencia, sino sólo la interpretación platónica de la verdad, es decir que lo verdadero es lo suprasensible. Heidegger llega afirmar incluso que mantiene el concepto platónico de verdad y sólo le da a lo verdadero otro contenido: «la diferencia entre verdad y apariencia vuelve a aparecer en otra forma». En realidad, y a pesar de que se señala que con la eliminación de lo superior también se elimina lo inferior, no se ha eliminado la estructura platónica de un arriba y un abajo. Lo que parece una expulsión (Herausdrehung) fuera del platonismo en realidad no lo es, sino que se enreda en lo que pretende superar, no en el platonismo en un sentido superficial sino en la «experiencia fundamental de la filosofía platónica». No hay pues expulsión alguna del platonismo, «ial contrario!».

La formulación de las lecciones originales es clara en el sentido de no dejar abierta la posibilidad, pero no aporta demasiados argumentos a su favor, que sólo podrán provenir de una elaboración más detallada de la cuestión de la verdad.

En el seminario dedicado a Nietzsche en $1937^{16}$, al mismo tiempo que las segundas lecciones, vuelve a aparecer varias veces la cuestión de la inversión y la expulsión. También aquí se presenta en primer lugar una cierta valoración del movimiento mismo de la inversión. Vista históricamente, la filosofía de Nietzsche es una «inversión del platonismo como contramovimiento respecto del nibilismo» ${ }^{17}$, es «el nihilismo más extremo y $s u$ superación». La oposición de Nietzsche al primado de lo suprasensible, en general al primado de los principios que se superponen al suceder, es lo que constituye su aspecto más revulsivo y, a la larga, positivo. Heidegger ve aquí un cierto desarrollo de la posición básica de Nietzsche ${ }^{18}$, que parte de una inmanencia biológica del representar, pasa por una universalización de esa concepción, y llega a una inversión del platonismo en conexión con la cuestión de lo ideal y del nihilismo, para, a su vez, desde allí salir de la contraposición entre verdad y apariencia, lo que constituiría el paso decisivo. Ya no hay sólo inversión, sino también salida, expulsión de la contraposición que remite el «ideal» a la «vida», en dirección al todo. Se abre así,

14. Nietzsche I 242/198.

15. GA 43, $261 \mathrm{~s}$.

16. GA 87: Nietzsche. Seminare 1937 und 1944.

17. GA 87,10 .

18. GA 87,14 
comenta Heidegger, la posibilidad de una experiencia del ente en total que pone en movimiento una esclerosis de dos milenios ${ }^{19}$.

A pesar de ello, la inversión sigue pesando, manteniendo la dependencia de lo que invierte ${ }^{20}$. Esta dependencia se basa ahora en su remisión a un principio activo, remisión que se mostrará fundamental en la derivación de la noción Nietzscheana de verdad respecto de la noción clásica. Efectivamente, la transformación propia de la inversión remite a la pura acción ${ }^{21}$, con lo que el ideal queda remitido a la vida, que sólo aceptará como diferencia la de los grados del poder. Éste es, para Heidegger, el paso metafísicamente más extremo de Nietzsche, que lo lleva al necesario caos de la pura acción de crear y no es más que la consecuencia de que su filosofía es desde un comienzo un platonismo invertido. La inversión consiste en apoyarse en la apariencia como realidad, con lo que el platonismo no es superado sino introducido con mayor fuerza en una forma invertida. La presunta expulsión no es más que la consecuencia de la inversión del platonismo, y por eso no es de ningún modo su superación ${ }^{22}$. En realidad, el eterno retorno es en cierto sentido la expulsión del platonismo ${ }^{23}$, pero se trata una «umkehrende Herausdrehung» (algo así como «expulsión que invierte») que se lleva consigo el platonismo, sólo que invertido. La salida resulta ser, entonces, una vuelta al inicio deformado, un final que vuelve a él. La consecuencia de la inversión es la desaparición de la contraposición estricta entre verdad y apariencia ${ }^{24}$, con lo que se produce una ilusión de salida, pero sólo en la medida en que lo verdadero, en cuanto apariencia necesaria, queda integrado en la auténtica realidad, lo que sigue sin ser una superación del platonismo. La única alternativa, anuncia Heidegger prospectivamente, sería la «transformación de la esencia de la verdad, el esenciar del ser como salto al ser-ahí (Erspringung des $D a$-seins $) »^{25}$. La cuestión decisiva será, pues, la transformación de la esencia de la verdad que deje lugar al esenciar del ser. Volveremos sobre ello.

También en los Beiträge alude Heidegger a la doble figura de la inversión y la expulsión. En la sección $91^{26}$ repite que la inversión implica quedarse enredado en la contraposición sensible-suprasensible, aunque, añade, «Nietzsche siente con seguridad la necesidad de que esa contraposición tiene que perder su sentido». En concordancia con lo anterior, en otro pasaje ${ }^{27}$ expresa que precisamente porque la filosofía de Nietzsche se comprende como inversión del platonismo, «cae de nuevo en él por la puerta trasera. Incluso allí donde sale del platonismo y su inversión, no llega a un cuestionamiento originario y superador por la verdad del ser y la esencia de la verdad».

Antes de continuar con la consideración de la inversión o superación del platonismo, haremos una referencia específica al concepto de apariencia (Schein), al que Heidegger dedica numerosas reflexiones, sobre todo en el seminario de 1937.

19. GA 87,15 .

20. GA 87,81 .

21. GA $87,160,169$.

22. GA 87, 169, 170, 171.

23. GA 87,174 .

24. GA 87,175 .

25. GA 87,81 .

26. GA 65, p. 182.

27. GA 65, n. ${ }^{\circ} 110$, pp. $218 \mathrm{~s}$. 
Esta cuestión ocupa un lugar central en la medida en que se acerca, por lo menos aparentemente, al concepto de fenómeno de la fenomenología. Tienen que leerse, por lo tanto, en la línea que proviene del $\mathbb{\$} 7$ de Ser y tiempo (y de sus formulaciones previas), en el que se hace un detallado análisis de la primacía del mostrarse respecto de la mera apariencia o de la noción de fenómeno como manifestación de algo oculto. Siguiendo esa línea, la primacía que otorga Nietzsche al concepto de apariencia respecto del de verdad podría traducirse en la primacía del fenómeno respecto de un ser en sí separado del aparecer, tal como la desarrolla la fenomenología. Por eso Heidegger podrá decir que la «apariencia, el aparecer, es, bien comprendido, el suceder fundamental del ser abierto de lo desoculto ${ }^{28}$. Pero esto, sin embargo, no ocurre en la medida en que el aparecer es comprendido no como «claro» (Lichtung), como «ahí» (Da), sino de un modo representativo, para remitirlo posteriormente a la «vida» ${ }^{29}$. En otras palabras: lo que aparece no es retenido como tal, como mostrarse, sino que, al concebirlo como algo representado, refiere finalmente a la vida y sus condiciones, lo que se traduce en último término en relaciones de fuerza.

Ya en la primera de las lecciones dedicadas a Nietzsche hace Heidegger una profunda reflexión sobre el sentido de la apariencia, que conlleva también una consideración crítica de las nociones Nietzscheanas de perspectiva e interpretación. A pesar de su propia advertencia acerca de lo fatal de la palabra «apariencia» $(\text { Schein })^{30}$, Nietzsche cae víctima de la confusión de este concepto. La afirmación de que «apariencia es la verdadera y única realidad de las cosas», debería querer decir, según Heidegger, no que la realidad es algo aparente, «sino que el ser real es en sí mismo perspectivista, es un llevar al aparecer, un dejar aparecer, es en sí mismo un aparecer ${ }^{31}$. Lo perspectivo sería entonces el auténtico mostrarse. Pero para comprender así el perspectivismo, debería verse como la inclusión en lo que aparece de la perspectiva dentro de la que aparece, algo así como la referencia del aparecer a los actos noéticos en la fenomenología. Esto es, sin embargo, lo que Nietzsche no hace con su concepto de perspectivismo, que por eso es puesto en cuestión en diversos pasajes del seminario de 1937. Lo perspectivo está visto sólo en función del ángulo determinado desde el que se realiza, para recalcar así su unilateralidad, y por lo tanto el carácter aparente de aquello a que se refiere. De este modo no se piensa el carácter mismo de la finitud que permite la direccionalidad y el abrirse de mundo. Lo que aparece queda entonces como mero parecer, como mentira, y no se ve, en cambio, lo que está más originariamente a su base: la unidad de claro y ocultamiento ${ }^{32}$. Los perspectivismos, dice Heidegger, tanto el de Nietzsche como el de Leibniz, no desarrollan el carácter propio del aparecer, el acontecer fundamental del ser abierto en lo desoculto, sino que se quedan en lo psicológico, en la relación sujeto-objeto.

De esa manera, lo que aparece queda remitido en último término a los datos sensibles. Sobre esta base critica Heidegger la noción Nietzscheana de interpretación. A diferencia de lo ya defendido en Ser y tiempo, no es el desarrollo de

28. GA 87, n. ${ }^{\circ} 101$, p. 109.

29. GA 87, n. ${ }^{\circ} 98$, p.108.

30. KSA XI, 40[52]. Citado en Nietzsche I, 247 s./202

31. Nietzsche I 248/202.

32. GA 87, n. ${ }^{\circ} 110$; cf. también n. ${ }^{\circ} 132$. 
una comprensión, sino que se ejerce sobre datos para sólo entonces dar lugar a la comprensión. La relación con el mundo es de interpretación en la medida en que se interpretan de modo diferente los datos presentes ${ }^{33}$. Frente a ello, Heidegger reivindica una noción de interpretación como despliegue o explicitación (Auslegung) de lo ya incluido en el darse comprensivo más primigenio. Esto se hace visible en la estructura del «como» (als), en la que lo decisivo no es el lugar desde donde se lo dice sino el hecho de que allí se muestre de modo originario el darse de algo como algo ${ }^{34}$. Previo a lo percibido es su carácter de «mundo». Sólo hay aparecer donde hay mundo ${ }^{35}$, que en realidad no aparece sino «mundea» (weltet). En la experiencia originaria del aparecer vamos más allá de la cosa, pero no en dirección a un en sí, ni siquiera en dirección de algo desconocido que se terminará por negar, sino en dirección del mundo, del «ahí». Pero mundo no es un aparecer, sino un abrir que al mismo tiempo se mantiene oculto. Así pues, de la previedad del mostrarse en un sentido no representativo se pasa a la previedad de un ámbito que lo permite (mundo), y que a su vez es en sí mismo un ocultamiento (tierra), o más bien la lucha en la que éstos comparecen.

Heidegger traza los supuestos desde los que Nietzsche habla de apariencia. En primer lugar, señala el platonismo, sólo que invertido, en el sentido antes comentado. Lo que esencialmente se mantiene del platonismo es una determinación de lo verdaderamente real desde una dimensión constitutiva, que ahora no es la de la figura del pensar (idea) sino la de la imposición de una identidad desde la «vida». Por eso, Heidegger la ve, en segundo lugar, como una transformación del platonismo en dirección subjetiva, algo que puede verse como una radicalización y naturalización de Kant. Lo que se presenta es el fenómeno, en la medida en que es una determinación impuesta no ya por una subjetividad trascendental como condición de posibilidad de la experiencia como tal, sino por un núcleo de fuerza para cumplir con sus necesidades de dominio. O sea, como condición de posibilidad de una experiencia particular. En la medida en que este punto de fuerza no puede ya ser comprendido como la constitución de un mundo de sentido en cuanto tal, todo depende de la constitución de ese punto de fuerza, que se interpreta de un modo fisiológico-biológico. Éste es el tercer supuesto que ve Heidegger en la noción de apariencia. Por último está el caos de las sensaciones en el sentido del «todo fluye». La acuñación de formas sólo es posible desde la suposición de un material informe, lo que ya estaba presente en la formulación kantiana. Hay que resaltar, sin embargo, que la conclusión de todo esto no es el mero rechazo, sino la necesidad de poner en cuestión sus supuestos para poder llegar a una auténtica confrontación ${ }^{36}$.

La discusión de la relación entre verdad y apariencia es retomada en la tercera lección sobre Nietzsche, de $1939^{37}$. La determinación de la esencia de la verdad como «ilusión» o apariencia está para Heidegger en una conexión esencial con la interpretación metafísica del ente y es, por lo tanto, «tan antigua e inicial

33. GA 87, n. 97.

34. Cf. sobre esto M. Heidegger, Ser y tiempo, $\mathbb{} 32$.

35. GA $87, \mathrm{n}^{\circ} 85$.

36. Cf. GA 87, n. $^{\text {os }} 106$ y 108.

37. La voluntad de poder como conocimiento. Recogida también en Nietzsche I. Las lecciones originales en GA 47. 
como la metafísica misma ${ }^{38}$. Está ligada con el surgir, mostrarse, llegar a la visión, y en ello radica su peso y su profundidad, aunque al mismo tiempo caiga presa de una dinámica que la condena al ocultamiento de su propio origen. En la transformación que acontece en la modernidad se supone la comprensión originaria como physis, si bien también se produce una transformación esencial ${ }^{39}$, que hace que se mantenga en el poder de una forma irreconocible. De lo que se trataría entonces es de remontarse a ese origen, para poder experimentar en él lo que necesariamente se ocultaba, es decir, no para negarlo por «metafísico» sino para trascenderlo hacia su propia condición. Lo que sucede en la metafísica es el «poder de la esencia de la verdad ${ }^{40}$.

La concepción de la verdad como ilusión tiene como supuesto la determinación tradicional de la verdad como corrección del representar ${ }^{41}$, pero ésta se transforma al comprenderse como una estimación de valor. La noción de valor sirve de intermediario para fortificar la tesis de remisión a la unidad de la vida, $y$, en definitiva, de la voluntad de poder. Efectivamente, en la medida en que se interpreta la verdad como una estimación de valor, la cuestión ya no es la de cómo se apresa algo exterior, sino el hecho de que se constituye en condición de la vida. Al plantearse la cuestión del origen de la distinción entre un mundo verdadero y un mundo aparente ${ }^{42}$, Nietzsche la remite a la estimación de que lo consistente y fijo es de mayor valor. Refleja así, comenta Heidegger, lo que guía a la tradición metafísica, pues esas son las condiciones que corresponden a la vida del hombre occidental. El modo en que se interpreta la esencia del ente (consistencia) surge del modo en que se concibe la vida misma: aseguramiento de sí.

En todo caso, la tesis de que la verdad es en esencia estimación de valor es «la consecuencia más oculta y extrema del primer inicio del pensar occidental $»^{43}$. Es la consecución de ese movimiento por el que la verdad es lo que queda a disposición del hombre, del representar, y pierde todo otro sentido. Por eso Heidegger interpreta la remisión de la verdad a una estimación de valor como una interpretación que se mueve dentro del marco de la verdad como corrección y como homoiôsis. En ese sentido, la propia interpretación que hace Nietzsche de la razón sería una especie de platonismo pensado modernamente, pues mantiene el carácter inventivo de la razón, aunque determina de modo diferente su proveniencia: el carácter de la razón está dado con la vida ${ }^{44}$. Se produce así una mera inversión del pensar griego, y no una auténtica confrontación que sea capaz de salir de la posición inicial, entendido esto siempre no en el sentido de dejarla simplemente atrás, sino en el de mostrarla en su carácter propio y poder destacar lo no pensado ${ }^{45}$.

Nietzsche afirma que la verdad pertenece a la vida misma, aunque no sea el valor más elevado: más allá de la verdad está el arte. Esta relación, que ya había ocupado un papel central en las primeras lecciones de 1936-37, representaría

38. Nietzsche I, 504/406.

39. Nietzsche I, 505/408.

40. Nietzsche I, 508 s./409.

41. Nietzsche I, 513/413.

42. Nietzsche I, 543/436

43. Nietzsche I, 547/439

44. Nietzsche I, 586/469.

45. Nietzsche I, 605/484 s. 
un primer intento de Nietzsche de crítica del platonismo, en el que mundo verdadero y mundo aparente intercambian sus papeles. Permanece, sin embargo, la distinción entre los dos mundos, y la inversión sólo puede realizarse sobre la base de esta distinción ${ }^{46}$. Pero ésta, afirma Heidegger, no es la posición final de Nietzsche, sino que en los dos últimos años se introduce en el abismo que allí se abre, por lo que la interpretación tiene que dar aún el paso decisivo.

En ambas determinaciones, la de la verdad y la del arte, se da una ambigüedad en los sentidos de verdad y apariencia. La verdad es, por un lado, fijación del devenir, y por otro, concordancia con el devenir (lo que permite decir que aquella verdad es falsa). La apariencia remite a la apariencialidad del arte, pero también al comparecer de nuevas posibilidades ${ }^{47}$. Finalmente, sin embargo, todos serán grados del error, todo será de alguna manera apariencia, con lo que se llega al extremo en el que la verdad comprendida metafísicamente alcanza su última esencia posible.

El paso decisivo se da cuando, habiéndose abolido el mundo verdadero y el mundo aparente, no desaparecen, sin embargo, verdad y apariencia, conocimiento y arte, pero se ha transformado la esencia de la verdad en dirección del proyecto conductor de la vida. Si esta interpretación coincide en lo esencial con la que se esbozaba en el seminario de 1937, ahora se prolonga en dirección de una determinación «extrema» de la esencia de la verdad. En efecto, la doble ambigüedad de verdad y apariencia remite a aquello que no es ni una ni otra, ni puede ser explicado a partir de ellas, y esto es lo que encarnan los «inmoralistas», quienes están más allá del bien y del mal, es decir, fuera de la distinción metafísica. El campo al que remite entonces es el de la "gran política», que constituye «la metafísica más propia de Nietzsche» ${ }^{48}$. En los «inmoralistas» se juega la decisión sobre la distinción entre mundo verdadero y aparente en la medida en que asumen la exigencia planteada por su abolición de «pensar hasta el extremo la determinación de la esencia de la verdad».

En este contexto vuelve Heidegger a la fábula de El crepúsculo de los ídolos. En primer lugar, recuerda que la respuesta que da Nietzsche al final de la fábula es «incipit Zaratustra», y Zaratustra es la figura del pensador que ha creado como lo extremo de la metafísica. Allí se vuelve necesaria una esencia de la verdad sobre la que no puede hablarse, porque de lo que se trata es de «actuar de modo pensante». Y puesto que el otro nombre es «incipit tragoedia», a lo que se alude es al hundimiento (Untergang) del héroe, es decir, de la metafísica, lo que no quiere decir simple terminación sino «acabamiento extremo de la esencia». El acabamiento sólo puede consistir en que la abolición de la distinción entre mundo verdadero y mundo aparente obliga a volver a la determinación metafísica de la verdad como homoiôsis, y a interpretarla como justicia (Gerechtigkeit) ${ }^{49}$. Al pensar hasta el extremo la esencia de la verdad se vuelve inevitable la idea de «justicia», en la que, con el derrumbamiento del en sí de lo ente, la esencia de la verdad como homoiôsis llega paradójicamente a «una exclusividad sin obstáculos». Esto es posible porque la homoiôsis no es ahora la igualación y reproducción de lo dado,

46. Nietzsche I, 617/494.

47. Nietzsche I, 620 s./496 s.

48. Nietzsche I, 629/503.

49. Nietzsche I, 633/505. 
sino que ha alcanzado su forma más esencial como asimilación al caos, que en su doble vertiente de fijación y transfiguración remite a una determinación desde la vida como voluntad de poder. La asimilación misma tiene que dar la medida, y esto es lo que Nietzsche llama «justicia» y constituye el acabamiento de la metafísica. Con la expresión «justicia», insiste Heidegger, no se está haciendo referencia a un concepto moral o jurídico, sino a la determinación de lo que es recto como proyección de la voluntad de poder. Se consuma así algo que no es otra cosa que la consecuencia interna de que la alêtheia haya permanecido impensada: la justicia, que consiste ante todo en pensar desde estimaciones de valor ${ }^{50}$, es el acontecimiento del abandono del ente por parte del $\operatorname{ser}^{51}$. La estimación de valor es la determinación de qué se pone como condición esencial de la vida y es por lo tanto aquello en lo que se basa la vida que se funda a sí misma ${ }^{52}$, constituyendo así el fundamento esencial de la verdad. Esto es lo que Heidegger llama «sobrepotenciamiento", que no constituye de ninguna manera un impulso ciego, pero es lo que está más allá del bien y del mal, y de la distinción entre mundo verdadero y mundo aparente $^{53}$. Ésta sería la «superación del platonismo", en la que se determina de modo la esencia del mundo y del hombre y se pone el fundamento de todo tipo de conformidad del hombre con el caos, tanto en la forma del conocimiento (verdad) como en la del arte (apariencia).

En las lecciones originales se insiste, en una recapitulación no incluida en el libro de $1961^{54}$, que con la caída de lo verdadero no desaparece la esencia de lo verdadero, sino que, al contrario, ahora aparece en su carácter más puro. En el conocimiento y el arte se produce el aseguramiento de la consistencia del hombre, lo que posibilita su propia esencia. El aseguramiento de la consistencia es la concordancia, homoiôsis, con el caos, que no es un disolverse en puro impulso sino el fijar y transfigurar que ordena e inventa.

En referencia a la idea de inversión y de expulsión del platonismo, es interesante resaltar que, en el momento en que quiere referirse a una auténtica superación del platonismo y, por ende de la metafísica, Heidegger vuelve a emplear expresiones relacionadas con aquellas. No se tratará de una inversión (Umdrehung) sino de un "giro» (Drehung), de un «girar que penetra (Eindrehen) en el otro fundamento como abismo». La «Kehre» (vuelta) heideggeriana es, de cierto modo, la alternativa de la inversión y la transvaloración.

En el pensamiento Nietzscheano, en cambio, tal como se dice en la parte final, no pronunciada, de las lecciones de 1939, que se incorporaría en el libro de 1961 al comienzo del segundo tomo, se produce un «suprimir que invierte» (umkehrende Auslöschen) la contraposición entre ser y devenir. Hay una primacía del devenir que sin embargo se convierte en la confirmación más extrema de la concepción de ser como volver consistente la presencia ${ }^{55}$. La esencia de la verdad inicial se transforma de una manera que equivale al apartamiento, no a la aniquilación, de su esencia. La verdad, convertida en justicia, en el sentido

50. Cf. Nietzsche II, 322 ss./260 ss.

51. Nietzsche I, 637/509.

52. Nietzsche I, 643/513.

53. Nietzsche I, $646 \mathrm{s.} / 516 \mathrm{~s}$.

54. GA 47, 261 ss.

55. Nietzsche II, 18/20. 
antes aludido, es voluntad de poder que posibilita el dominio incondicional de la tierra.

La inversión es el primer paso de lo que se transformará en «transvaloración» (Umwertung), en la medida en que la idea quede transformada en valor. De este modo, el platonismo, invertido y convertido sin embargo en un plano único, queda refrendado, endurecido y enceguecido.

En resumen, en la destrucción del chorismós platónico por parte de Nietzsche, Heidegger ve sobre todo la remisión de las nociones de verdad y ser a una instancia productora que no tiene más criterio que su propio aseguramiento y crecimiento. Esta es una instancia no sustancial, que no tiene el carácter de «ser», sino que es más bien un proceso que instala las fijaciones correspondientes como modos de apoyarse en ellas para volver a superarlas. La disolución de lo que es como presencia inmediata remite a un proceso productivo que no deja ya rastro de una dimensionalidad previa al acontecer.

Habría que señalar por último, aunque más no sea de modo muy general, la concepción de verdad que desarrolla el propio Heidegger en este contexto y que sirve de base a todas las anteriores críticas. Ésta aparece de modo explícito en los Beiträge, así como en las lecciones de $1938^{56}$, que tratan precisamente sobre la verdad y que son las que están más cercanas a la obra anterior. Se muestra también en más de un pasaje que ya hemos citado, aunque, siguiendo con el criterio empleado por Heidegger para las «lecciones históricas», esto ocurre sólo de manera tangencial. Incluso en las citadas lecciones de 1938, lo más relevante aparece en el Apéndice, que era una primera versión que finalmente no fue leída. Tomaremos este texto como punto de apoyo.

Allí señala, tal como lo había hecho ya en De la esencia de la verdad, que la verdad como corrección, es decir como regirse por el ente que aparece, supone que el ente se muestre, que se dé la apertura del ente, el «claro» o «despejamiento» (Lichtung). Pero este claro está rodeado no simplemente por lo oculto, lo que permite ya hablar de la verdad como desocultamiento (alêtheia), sino por lo que se oculta (Sichverbergendes), que resulta así la dimensión fundamental. El claro no está sólo limitado por lo que se oculta sino que es «claro para lo que se oculta» (Lichtung für das Sichverbergende): el ocultarse es una caracterización esencial de ser mismo. Así pues, si la originaria dimensión de apertura fue experimentada ya inicialmente como alêtheia, ahora se nos muestra como el «vacilante ocultarse» que esencia en el claro. La verdad no es simplemente desocultamiento del ente sino "claro para el vacilante ocultarse» ${ }^{57}$. Este ocultarse en el corazón de la alêtheia es lo que ha llevado a que la verdad se reduzca finalmente a corrección y desaparezca la dimensión posibilitante. Una recuperación de ese origen sólo puede querer decir, por lo tanto, experimentar ese ocultarse de ser. Así como es imposible vivir nuevamente el asombro de que el ente sea, pues su carácter de ser se ha vuelto obvio e indiferente, así también el mero señalamiento del desocultamiento no haría más que intentar repetir la historia que ha llevado a esa indiferencia. La experiencia inicial del desocultamiento, absorbida primariamente en la maravilla de que el ente sea, asombro que aún hunde sus raíces en el ocultamiento originario, tendió a borrarlo, a ignorarlo y dejar sólo

56. Grundfragen der Philosophie. Ausgewälte «Probleme» der «Logik» (GA 45).

57. GA 45, 211. 
la presencia y su génesis. Un nuevo inicio sólo puede partir de ese ocultamiento original y de la forma en que se presenta en la situación de crisis final: el retirarse o rehusarse de ser.

Mientras que la vivida experiencia del sinsentido es retrotraída por Nietzsche a la falta de capacidad de imponer un sentido o, a lo sumo, a la fuerza que no se deja imponer uno (dos formas del nihilismo), aquí se pone en cuestión la posibilidad de imponer un sentido, afirmando más bien la necesidad de romper con ese intento para poder acceder a una experiencia diferente, la del «ahí», la del claro, condicionado a su vez por la substracción de ser. Hacer esta experiencia exige responder a lo que requiere en esa apertura, y esa respuesta será la fundación (en una segunda instancia) de la verdad del ser en los entes.

La repetición de la experiencia del primer comienzo, que no quiere decir volver a él, es decisiva en la medida en que se experimente en el presente la incapacidad de estar a la altura de lo que allí sucedió. Volver a las «experiencias en las que esas categorías fueron forjadas ${ }^{58}$, equivale ahora a intentar saltar a ese ámbito de mostración y substracción, lo cual sólo es posible gracias a la penuria que se instaura cuando la débil protección de ese ámbito se desmorona y sobreviene la indigencia que Nietzsche había caracterizado como nihilismo.

Para Heidegger, en la noción Nietzscheana de justicia llega a su culminación y a su vaciamiento la idea de verdad como corrección, como un «dirigirse a» que sólo deja ser la presencia inmediata de lo que en cada caso aparece. La verdad, en la medida en que ha perdido su esencia originaria, se pone al servicio de la vida, que no es más que el nombre para el continuo aseguramiento de sí mismo. Lo que distingue a la verdad metafísica que aquí llega a su fin no es la igualación con un supuesto enfrente, sino la pérdida de la dimensión del aparecer, de lo abierto mismo, en beneficio de una instancia productora y dominadora. En el aparecer, la dimensión de lo abierto, la Lichtung, se substrae, aunque en un primer momento quede en ella algo de esa experiencia originaria. En la medida en que desaparece de manera más radical, queda a disposición de la vida-sujeto, perdiendo todo carácter de verdad como desocultamiento, para pasar a ser función de una instancia que sólo pretende ejercer su poder.

Si en esa situación presente surge algo así como una penuria, como una necesidad, aunque en su extremo sea más bien la penuria de la falta de penuria, entonces la recuperación de esa experiencia del claro sólo podrá llevarse a cabo desde una transformación del carácter con que éste mismo se experimenta. El claro tiene que incluir su propio ocultamiento, convertirse en el claro del ocultarse, paso en el que el ocultamiento puede llegar a mostrarse como cobijo (Bergung).

Heidegger interpreta a Nietzsche en relación con el platonismo en la medida en que lo que está en juego, y en Nietzsche llega a una caracterización extrema y ciertamente plurisémica, es la distinción entre el aparecer y una dimensión que lo supera y le sirve de fundamento, es decir, la cuestión del sentido del «metá» de la metafísica. La «inversión» Nietzscheana puede entonces significar, en primer lugar, como habíamos visto, que el mundo aparente es el mundo verdadero en el sentido de que lo auténticamente verdadero es lo que en la metafísica se califi-

58. M. Heidegger, Ser y tiempo, $\mathbb{} 6$. 
caba como aparente, mientras que el mundo de lo metafísicamente «verdadero» no es más que una apariencia. Si nos quedáramos allí, no tendríamos más que el nivel propio del positivismo. Pero a partir de allí, se podría seguir una línea interpretativa que sólo en parte se toca con la de Heidegger. El mundo «verdadero», que en principio quedaba abolido, vuelve a aparecer en el lenguaje mismo, en la consideración corriente de las cosas, con lo que la crítica, no se refiere ya sólo a las entidades o principios primeros, sino a la ontología sedimentada en el lenguaje. Es en relación a esto que Nietzsche dice que el verdadero nombre de lo real es apariencia, no porque lo siga siendo en referencia a un mundo verdadero sino porque no puede tener el carácter que se le atribuía a ese mundo verdadero (identidad, «ser»). La afirmación contradictoria de la abolición del mundo aparente sólo querría decir entonces que no seguiría siendo aparente en el antiguo sentido, pero no por ello mantendría en sí el carácter de lo verdadero, es decir, no puede heredar las características del mundo-verdad.

La cuestión decisiva es la de si esto puede considerarse como un radical antiplatonismo, es decir, como una auténtica salida de la metafísica. Heidegger lo pone en cuestión en la medida en que el mundo único que queda, aunque sea pensado como no idéntico, no sustancial, remite a una instancia global que se autosustenta (la voluntad de poder). La remisión a esta instancia constituye un cierre metafísico de la metafísica, en la medida en que se instituye un proceso único que integra en sí y anula la diferencia. La inmanencia resultante, que parece implicar una superación del platonismo y de la metafísica, en cuanto va más allá de sus tradicionales dualidades, no dejaría de ser una ilusión, y una afirmación sin límites de la metafísica, en la medida en que subyace el elemento productivo que absorbe en sí la diferencia. Ésta estaba ya anulada en cuanto quedaba ocupada por la diferencia entre un mundo aparente y un mundo verdadero, o, en general, entre un mundo condicionado y su «verdad», pero al mismo tiempo, se mantenía allí un cierto resto de la diferencia original. En la medida en que ésta desaparece («muerte de Dios»), se produce un movimiento extremo y ambiguo. Desaparece la diferencia en favor de una uniformidad productiva y, al mismo tiempo, el hecho de que la trascendencia, la diferencia, quede reducida a nada deja aparecer la «verdad» de la metafísica: los principios son nada, pero en eso mismo, además de la destrucción de sus pretensiones, radica la posibilidad de que se instaure la diferencia radical, la que no puede identificar el «otro término» como un ente o un principio. La nada tendrá ese carácter bifronte.

Más allá de la equívoca cuestión de si Nietzsche es interpretado correctamente, lo que se plantea es si la destrucción de la sustancialidad, que Nietzsche identifica con «ser» puede abrir a una dimensión no simplemente productiva y de autoacrecentamiento, si el ámbito del arte, entre otros quizás, puede entenderse como una manera de recuperar cierta otredad que quedaba ahogada en el plano del «conocimiento». Esto equivaldría a preguntarse si frente a la totalización sistémica que vemos acrecentarse día a día, el aprovechamiento de las rupturas que esas mismas totalizaciones provocan consiste en algo más que una huída hacia delante que en definitiva favorece el funcionamiento del conjunto. Una interpretación alternativa podría partir de que la afirmación de la verdad como fijación, falaz, del devenir, en cuanto es algo que corresponde, no a la vida en general, sino al tipo de vida que aparece en el hombre occidental, sería más bien un signo de debilidad, algo que debe ser superado. La superación, que acontece 
con la aceptación de la ficción y con la rehabilitación del arte y la apariencia, sería una contrafigura que destruiría la noción de verdad como aseguramiento de sí, en beneficio de una ruptura de toda identidad, y por lo tanto también de la de cualquier instancia de tipo subjetivo. Para ello sería necesario entender en una clave totalmente diferente lo que Nietzsche denomina «voluntad de poder». Lo decisivo sería entonces si la afirmación de la apariencia, la destrucción de toda instancia idéntica como originaria puede valer como una auténtica reflexión y «superación» del pensamiento metafísico ${ }^{59}$.

Heidegger, en su interpretación, encadena por el contrario las figuras de la fijación y la disolución y las une como dos movimientos solidarios que tienden al mayor aseguramiento de sí. Desde su lectura podría decirse que la anterior afirmación de la diferencia no llega a la profundidad suficiente y toma la disolución de la entidad, que es un producto de la disolución de la instancia metafísica, como un fenómeno originario. Consecuentemente, la anulación del metá sólo da lugar a un juego continuo de las diferencias. Aún si no se lo remite a una unidad originaria, o a un proceder originario (voluntad de poder), queda sólo el continuo descolocamiento que no accede a la dimensión negativa primaria.

En cualquier caso, la cuestión principal no es la de sí Nietzsche responde más a lo uno o lo otro, sino la de cuál es la perspectiva que permite pensar mejor la época. Si se trata del movimiento globalizante que sólo deja el límite casi inexperimentable de una nada, y en ese sentido requiere de un paso atrás, o de si en él anida una diferencia que desmarca en cada caso el valor de la identidad, y en ese caso, lo requerido sería más bien la liberación de ese potencial desestabilizador.

59. Creo que esto es lo que han intentado, de manera diferente, aunque esencialmente cercanas, Deleuze y Derrida. 